\title{
Subdural Haematoma and Effusion in Infancy
}

\author{
KENNETH TILL,* M.A., M.B., B.CHIR., F.R.C.S
}

Brit. med.F., 1968, 3, 400-402

\begin{abstract}
Summary : Analysis of $\mathbf{1 1 6}$ cases of subdural haematoma and effusion in infancy showed that in $40 \%$ trauma was involved and in 5\% meningitis was an aetiological factor; in the remainder there was no known antecedent disease. Apart from retinal or subhyaloid haemorrhages there were no clinical features pathognomonic of the condition, though vomiting was the commonest presenting symptom and a tense fontanelle the commonest finding 'on examination. Treatment by subdural pleural shunt operation, which allows the fluid to drain into the chest, where it is absorbed, was found to be effective, and there is no longer any justification for the older method of removal of the subdural membrane by craniotomy.
\end{abstract}

\section{Introduction}

Subdural collections of fluid in infancy are familiar to all paediatricians and neurosurgeons, the condition being by no means rare. Nevertheless, several important features of the condition remain conjectural or controversial. In many cases the cause and mode of formation of the fluid are quite unknown. There is still no agreement about the best method of treatment, and there are very few published accounts of any follow-up survey. For these reasons a survey was carried out on a personal series of 116 patients treated by one of two distinct methods and followed up for a long period.

Subdural effusion or haematoma may be defined as the accumulation of fluid between the dura and the arachnoid mater of the cerebral hemispheres. This fluid may be pure blood, as in the acute haematoma following a head injury, or it may be a watery fluid varying in colour from pale yellow to deep brown and always containing an amount of protein far in excess of that found in cerebrospinal fluid. The fluid collection may be loculated, but more commonly it extends over both hemispheres from frontal to occipital poles. The space occupied by this fluid is often bounded by a membrane. Over the arachnoid mater this is extremely thin and transparent, but it is not adherent. Under the dura the membrane may be up to $0.5 \mathrm{~mm}$. thick, and is often well supplied with blood vessels. It is not adherent to the overlying dura.

The infantile type of subdural effusion so far referred to should not be confused with those lesions found in later childhood to which the term "juvenile subdural haematoma" has been applied. This is usually a unilateral collection of fluid often confined to the middle cranial fossa, the fluid being almost identical with cerebrospinal fluid and bounded by a very thin transparent membrane.

\section{Present Series}

Aetiology.-Trauma is undoubtedly responsible for a high proportion of the cases of infantile subdural effusion. Only 21 of the infants in this series had a history of head injury, but the presence of skull fracture, fracture of other bones, or of bruising of the scalp made it almost certain that at least 46 $(40 \%)$ of them had been injured in the recent or distant past.

* Neurological Surgeon, the Hospital for Sick Children, Great Ormond Street. London W.C.1, and University College Hospital, London
W.C.1.
In six patients the effusion appeared to be a complication of meningitis. In the remaining $64(55 \%)$ patients the effusions were acquired without any known antecedent disease.

\section{Clinical Features}

Of the 116 patients 70 were male and 46 were female. The average age was 5.7 months. With the exception of retinal or subhyaloid haemorrhages there is no symptom or sign which can be regarded as pathognomonic of subdural effusion in infancy. Thus confirmation of the diagnosis can be obtained only by finding fluid in the subdural space. Vomiting was the most common symptom in the present series, occurring in 70 of the infants (Table I). It was also the initial symptom in the greatest number (Table II). Seizures occurred in 60 infants and were the presenting sign in 36 of them. Table I summarizes the major symptoms or signs, and shows that raised intracranial pressure should be strongly suspected in most of the patients with these features. The most commonly encountered abnormality on examination was a tense fontanelle (Table III), while retinal or subhyaloid haemorrhages occurred in 54 cases. The latter figure would undoubtedly be higher if more time had been spent examining the fundi of these babies. In only 13 of the patients was a fracture seen in the skull $x$-ray film, while 17 had fractures of bones elsewhere in the body. In every infant it was possible to pass a short bevelled needle through the scalp and anterior fontanelle. The protein content of the fluid removed in this series varied considerably-from several hundred $\mathrm{mg} . / 100 \mathrm{ml}$. up to $8 \mathrm{~g}$. in two patients, the average being 2 g. $/ 100 \mathrm{ml}$.

TABLE I.-Major Signs and Symptoms in 116 Cases

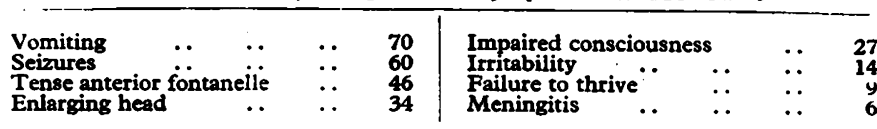

TABLE II.-Initial Sign or Symptom in 116 Cases

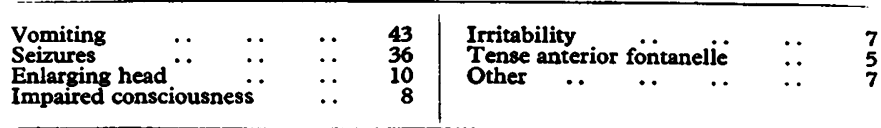

Table III.-Clinical Findings in 116 Cases

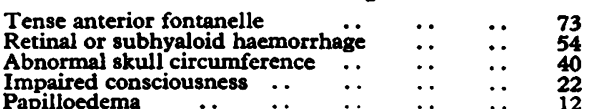

\section{Treatment}

If the radiographs taken after diagnostic aspiration of fluid and air replacement showed a subdural space which was less than $1 \mathrm{~cm}$. deep aspiration was repeated at intervals of 24 or 48 hours. In this series 19 of the patients were cured by aspiration alone. When the depth of the subdural space was shown initially to be greater than $1 \mathrm{~cm}$. the treatment was by operation, either by removing the subdural membrane by craniotomy or by performing a subdural pleural shunt operation. In the latter procedure soft rubber catheters are inserted into the subdural space on each side and carried through a subfascial channel to the chest, where the lower ends of the tubes are 
placed in the space between the parietal and the visceral pleura. The subdural fluid is then delivered slowly into the chest, where it is absorbed.

The babies treated by the shunt operation were usually readmitted after several months in order to remove the tubes. In this series there were no postoperative deaths from either craniotomy or subdural pleural shunt.

At follow-up examination particular note was taken of the children's intelligence. Table IV shows that nearly equal groups of children treated in these ways were available for comparison. In the group treated by shunt operation a higher proportion were found to develop with normal intelligence, though the follow-up period for these patients was shorter.

\begin{tabular}{|c|c|c|c|c|c|c|c|}
\hline $\begin{array}{l}\text { Method of } \\
\text { Treatment }\end{array}$ & $\begin{array}{l}\text { No. } \\
\text { of } \\
\text { Cas: }\end{array}$ & $\begin{array}{l}\text { Length } \\
\text { of } \\
\text { Follow- } \\
\text { up } \\
\text { Period }\end{array}$ & $\begin{array}{l}\text { Average } \\
\text { Follow- } \\
\text { up } \\
\text { Period }\end{array}$ & $\begin{array}{l}\text { Normal } \\
\text { Intelli- } \\
\text { gence }\end{array}$ & $\begin{array}{c}\text { Educa- } \\
\text { tionally } \\
\text { Sub- } \\
\text { normal }\end{array}$ & $\begin{array}{c}\text { Ineduc- } \\
\text { able }\end{array}$ & Dead \\
\hline $\begin{array}{l}\text { Craniotomy } \\
\text { only }\end{array}$ & 42 & $\begin{array}{c}3 \text { months } \\
\text { to } \\
9 \text { years } \\
4 \text { months }\end{array}$ & $\begin{array}{l}5 \text { years } \\
4 \text { months }\end{array}$ & $66 \%$ & $21 \%$ & $7 \%$ & $7 \%$ \\
\hline $\begin{array}{l}\text { Subdural- } \\
\text { pleural } \\
\text { shunt only }\end{array}$ & 34 & $\begin{array}{l}2 \text { months } \\
\text { to } \\
3 \text { years } \\
11 \text { months }\end{array}$ & $\begin{array}{l}1 \text { year } \\
6 \text { months }\end{array}$ & $86 \%$ & - & $11 \%$ & $3 \%$ \\
\hline
\end{tabular}

\section{Discussion}

There are three main causes of infantile subdural effusion: trauma, meningitis, and unknown factors. With the first cause the sequence of events may be as follows. The baby's skull is easily deformed and is elastic, while the underlying brain is very soft and easily displaced. The draining veins which run from the cortex through the arachnoid to reach the venous sinuses of the dura are numerous and thin-walled. It is probable that at the moment of injury one or more draining veins are ruptured and lead to the formation not only of subarachnoid haemorrhage but also of a haematoma in the subdural space. The two meninges are easily separated by the haematoma and bleeding continues until it is arrested by the rising intracranial tension. The skull may similarly be deformed during labour so that the delicate bridging veins between cerebral cortex and dural sinuses may be stretched and torn. The process is not a simple one, and it is likely that as the haematoma grows further veins are torn. More commonly the fluid found at the time of diagnosis is yellow, contains much protein, and covers the whole of both hemispheres. It is usually bounded by a thin membrane, the outer layer of which lies under the dura and tends to be much thicker than the inner layer lying over the arachnoid. There seems little doubt that this lesion is derived from a subdural haematoma which had developed weeks or even months earlier.

It has been suggested that the subdural haematoma clots and is then walled off by a membrane of invading connective tissue, the clot then becoming liquefied and breaking down. The membrane is semipermeable, so that more water is imbibed as the osmotic pressure of subdural fluid increases with the breakdown of the blood. This theory is attractive and may be correct in many patients. Nevertheless, it does not explain those effusions which follow meningitis, nor the occasional findings of a subdural effusion without membrane formation early after the head injury and long before a blood clot could have broken down. It is possible that a subdural haematoma is in some cases made more aqueous by a leakage of cerebrospinal fluid through the underlying arachnoid membrane. It must be admitted, however, that there is no satisfactory explanation in many cases, though trauma is an important factor in the majority.

Because the skull of a baby is so elastic, the absence of fracture is not evidence against there having been a head injury. In all cases a search for injuries elsewhere in the body should be made, the difficulty of diagnosing fractures in the long bones of small infants being only too well known.

Studies in the U.S.A. and in Europe have shown that the most common form of meningitis to give rise to subdural collections of fluid is that due to Haemophilus influenzae, the remainder usually being due to strains of Pneumococcus. The mode of formation of fluid in these cases is unknown. It is possible that very active treatment with numerous lumbar punctures (and hence with reduction of intracranial tension) may encourage the formation of subdural fluid.

\section{Presentation}

The duration of symptoms is impossible to assess in many cases because the onset of the disorder is often undramatic. Nearly half the patients in the present series had a history of less than a week, while in the remainder it was from 2 to 10 weeks.

It has been said that the skull shape of a hydrocephalic child tends to be globular, while the shape when a subdural effusion is present tends to be flattened on the vertex and broadened from side to side. This has not proved to be a useful point of difference in the present series. The first or initial symptom was vomiting or convulsions in the majority of patients. The non-specificity of the presenting symptoms no doubt accounts for the initial delay in diagnosis.

With very rare exceptions retinal or subhyaloid haemorrhage does not occur in babies unless a subdural effusion is present or unless there has been a recent and very definite head injury. This sign may therefore be considered almost pathognomonic, and should always be sought in babies who are vomiting or having seizures.

In half of the patients plain $x$-ray films of the skull suggested raised intracranial pressure as shown by separated sutures. Unfortunately it is not always possible to be confident that there is abnormal suture separation in young babies.

The diagnosis can be confirmed only when fluid is found between the dura and the arachnoid mater. Even so, the insertion of a needle through the anterior fontanelle clearly involves the risk of introducing infection or of causing haemorrhage from dural or cortical vessels. Indeed, it appears probable that subdural haematomas are occasionally caused by such a procedure. It is my view that a clinical situation which is thought to justify diagnostic needling is one which also warrants ventriculography if the attempt at finding subdural fluid fails. The inherent risks of needling, small though they be, together with

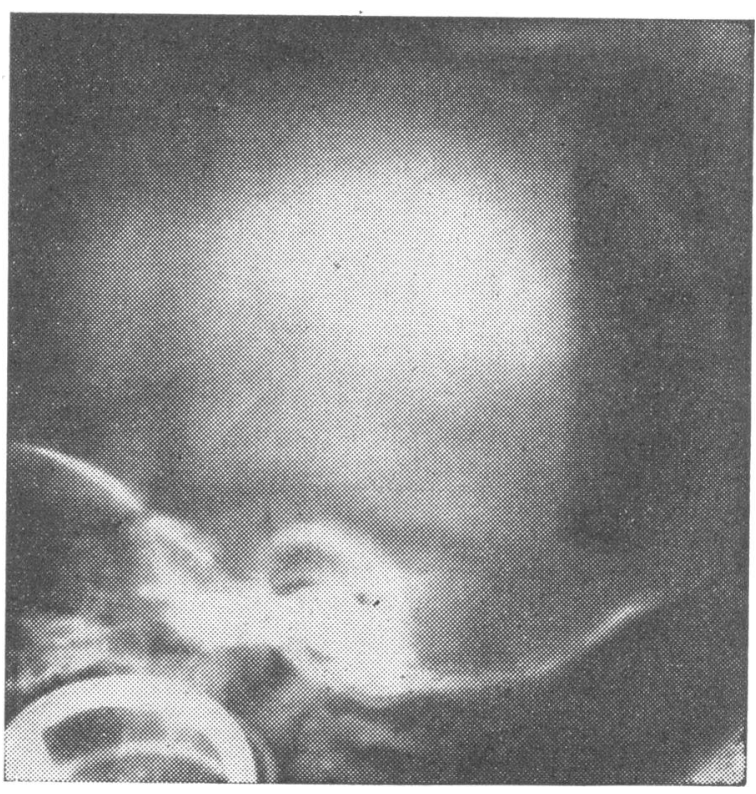


the possible need for later ventriculography, mean that the whole procedure should not be undertaken by one who is not sufficiently trained and experienced. The temptation to use subdural needling indiscriminately as part of a battery of tests must be firmly resisted.

It is essential at the first diagnostic aspiration to replace part of the removed fluid by air so that later $x$-ray films will serve to differentiate between the occasional case of gross hydrocephalus with very thin cortex, the porencephalic cyst lying near the anterior fontanelle, and the true subdural effusion. Such radiographs are also valuable in assessing the size of the effusion and hence judging whether repeated aspiration is likely to succeed in effecting a cure (see Fig.).

\section{Treatment}

Occasionally after successive aspirations the quantity of fluid diminishes rapidly, and subsequent radiographs after air replacement confirm that the subdural space is diminishing. Cure of the condition by aspiration is, however, uncommon, and is particularly unlikely in those babies who have had the fluid for more than a few weeks, so that a well-formed membrane is present. Sherwood (1930) introduced the idea of removing the subdural membrane by craniotomy, a technique which has been modified only in minor respects since it was first practised. The procedure can be formidable, and hazardous. Though operative deaths are now extremely rare, it is difficult to be enthusiastic about such a major operation on a baby. The outer membrane is often well formed and easily removed. It does, however, usually envelop both cerebral hemispheres, and therefore cannot be safely reached even through a large craniotomy opening. The inner membrane is sometimes so thin as to be almost unidentifiable, and again its removal must be far from complete. There are often bridging veins between the outer and inner membranes so that dissection at a distance from the craniotomy opening is sometimes hazardous. Fortunately this method of treatment apparently in many cases allowed expansion of the brain and the disappearance of subdural fluid.

In other patients, especially where there has been a substantial increase in head size, the brain is never able to expand sufficiently to fill the available space and the subdural collection of fluid inevitably remains. This led Ransohoff (1957) to perform a shunt operation in order to carry the fluid elsewhere over a long period of time, during which the disproportion between brain and skull could be corrected. He also mentioned that a shunting operation was carried out because craniotomy had failed to lead to a satisfactory reduction in intracranial pressure. In my view, however, it is probable that such failure is not uncommon whether or not disproportion exists between brain and skull. For this reason in recent years all subdural effusions have been treated by a subdural pleural shunt operation.

When the initial flow of fluid is large or when absorption is slow there may be temporary respiratory embarrassment. The babies are certainly in a better postoperative condition than those treated by craniotomy and the period of time in hospital is very much reduced. It is probable that the tubes (which do not require a valve) function for only a few weeks while the brain expands. The inner and outer subdural membranes either fuse or disappear, and the subdural space is eventually obliterated.

The actual development of the subdural effusion is only one factor of several which will determine the long-term quality of survival. Possibly the formation of subdural membranes is important, though there is no convincing proof of this. It can be accepted that failure to deal with the subdural fluid is likely to impair cerebral maturation, but the ultimate prognosis is related more to the underlying cortical damage which may have been inflicted at the time of the original injury or the attack of meningitis as the case may be.

The incidence of seizures and of mental retardation after treatment is probably independent of the method of treatment used. Shulman and Ransohoff (1961) provided results of small groups of patients treated either by craniotomy or by subdural pleural shunt. They found no significant difference in the proportions of children who were retarded or who suffered from seizures. The follow-up of patients in the present larger series indicates that the treatment by subdural pleural shunt may be superior to craniotomy. Nevertheless, the followup period is shorter here, so that assessment of impaired intelligence is more difficult and less accurate. There is no indication that treatment by craniotomy is in any way superior, and it is concluded, therefore, that this more elaborate procedure should be abandoned in favour of the simpler and less traumatic operation of subdural pleural shunt.

\section{REFERENCES}

Ransohoff, J. (1957). Pediatrics, 20, 561.

Sherwood, D. (1930). Amer. F. Dis. Child., 39, 980.

Shulman, K., and Ransohoff, J. (1961). f. Neurosurg., 18, 175.

\title{
Relation between Headaches from Oral Contraceptives and Development of Endometrial Arterioles
}

\author{
ELLEN C. G. GRANT,* M.B., CH.B., D.OBST.R.C.O.G.
}

\begin{abstract}
Summary : The incidence of headaches during the first $\checkmark$ year on oral contraceptives correlates closely with the incidence of well-developed arterioles in endometrial biopsy specimens. This relationship appears to depend on the ratio between progestogenic and oestrogenic components of the pill as well as the particular steroids. Therefore endometrial biopsies are useful for assessing the vascular response to an oral contraceptive and also provide a short cut to clinical evaluation of new formulations.
\end{abstract}

- Medical Officer, Council for the Investigation of Fertility Control, 27-35 Mortimer Street, London W.1.

\section{Introduction}

For the past six years clinical and endometrial studies have been carried nut as part of the. Council for the Investigation of Fertility Control central trial to evaluate new oral contraceptives. After the first year it was clear that, while dysmenorrhoea and premenstrual tension improved, headaches became more troublesome with Anovlar therapy (Mears and Grant, 1962). Groups of thick-walled arterioles were found in endometrial biopsy specimens obtained from women with these headaches (Grant, 1964). This observation was confirmed by Mazhar et al. (1965). In the normal cycle spiral arterioles and venous sinusoids develop in the late secretory phase, as described by 